\title{
Proteomic Analysis of the Effect of Extremely Low- Frequency Electromagnetic Fields (ELF-EMF) With Different Intensities in SH-SY5Y Neuroblastoma Cell Line
}

\author{
Mostafa Rezaie-Tavirani ${ }^{1}$, Hadi Hasanzadeh ${ }^{2 *}$, Samaneh Seyyedi ${ }^{3}$, Hakimeh Zali ${ }^{4^{*}}$ \\ ${ }^{1}$ Proteomics Research Center, Shahid Beheshti University of Medical Sciences, Tehran, Iran \\ ${ }^{2}$ Cancer Research Center and Department of Medical Physics, Semnan University of Medical Sciences, Semnan, Iran \\ ${ }^{3}$ Cancer Research Center, Semnan University of Medical Sciences, Semnan, Iran \\ ${ }^{4}$ Faculty of Paramedical Sciences, Shahid Beheshti University of Medical Sciences, Tehran, Iran
}

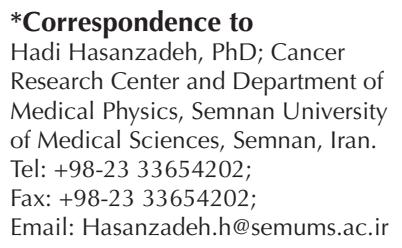

Published online 28 March 2017

\begin{abstract}
Introduction: During the last 3 decades, human is exposed to extremely low frequency electromagnetic fields (ELF-EMF) emitted by power lines and electronic devices. It is now well accepted that ELF-EMF are able to produce a variety of biological effects, although the molecular mechanism is unclear and controversial. Investigation of different intensities effects of $50 \mathrm{~Hz}$ ELF-EMF on cell morphology and protein expression is the aim of this study.

Methods: SH-SY5Y human neuroblastoma cell line was exposed to 0.5 and $1 \mathrm{mT} 50 \mathrm{~Hz}$ (ELF-EMF) for 3 hours. Proteomics techniques were used to determine the effects of these fields on protein expression. Bioinformatic and statistical analysis of proteomes were performed using Progensis SameSpots software.

Results: Our results showed that exposure to ELF-EMF changes cell morphology and induces a dose-dependent decrease in the proliferation rate of the cells. The proteomic studies and bioinformatic analysis indicate that exposure to $50 \mathrm{~Hz}$ ELF-EMF leads to alteration of cell protein expression in both dose-dependent and intensity dependent manner, but the later is more pronounced.

Conclusion: Our data suggests that increased intensity of ELF-EMF may be associated with more alteration in cell protein expression, as well as effect on cell morphology and proliferation.
\end{abstract}

Keywords: ELF-EMF; Proteomics; Neuroblastoma; Protein expression; Intensity. to the biological effects of ELF- EMF have been published, and some hypothetical mechanisms have been presented. ${ }^{8}$ A limited number of these studies have demonstrated that ELF-EMF promotes carcinogenic effects. Some available evidence showed that exposure to ELF-EMF can either enhance or inhibit cell proliferation and apoptosis., ${ }^{910}$ Several studies indicated that ELF-EMF exposure leads to alteration of chromosomal regulation and structure. ${ }^{11-13}$ Moreover, other in vitro studies suggested that ELF-EMF can change the expression of some protein involved in control of cell proliferation processes, ${ }^{14,15}$ while others demonstrated that exposure to ELF-EMF has no effects on cell proliferation, DNA replication andregulation. ${ }^{16}$ The results of these studies are different and may correspond to the opposite effects. Some of these conflicting 
data might be due to differences in frequency, intensity, duration and also certain type of cell lines. ${ }^{17}$ Generally, despite profound studies, there has not been any accepted molecular mechanism to explain the carcinogenic effects of ELF-EMF. ${ }^{18}$ Proteomics is a powerful tool to elucidate underlying mechanism of exposed cells.

In this study, we investigated the possible effects of $50 \mathrm{~Hz}$ ELF-EMF, with different intensities $(0.5$ and $1 \mathrm{mT})$ on cell protein expression, proliferation and morphology, using proteomics in SH-SY5Y- human neuroblastoma cell line.

\section{Methods}

Cell Lines and Cultures

SHSY5Y cells (human neuroblastoma cell line) were purchased from the national cell bank of Iran (NCBI, number: C611) and cultured in RPMI: Ham's F12 (1:1), 2 mM glutamine, $1 \%$ non-essential amino acids (NEAA), 15\% fetal bovine serum (FBS), 100 units/mL penicillin and 100 $\mu \mathrm{g} / \mathrm{mL}$ streptomycin. The cells were incubated at $37^{\circ} \mathrm{C}$ in a humidified atmosphere of $5 \% \mathrm{CO}_{2}$ and were seeded into T75 flasks. When the cells grew into approximately $70 \%$ of confluence (in exponential growth phase) at a density 3 $\times 10^{5}$, they were chosen for the experiments.

\section{Exposure System}

EMF exposure system produced homogenous sinusoidal ELF-EMF, with intensity of $0.5-2.0 \mathrm{mT}$ and frequency of $50 \mathrm{~Hz}$, which was generated with a Helmholtz coil. The system was designed to be embed inside the incubator and guarantee standard cell culture condition during exposure $\left(37^{\circ} \mathrm{C}\right.$ and $\left.5 \% \mathrm{CO}_{2}\right)$. Control and exposed Human $\mathrm{SH}-\mathrm{SY} 5 \mathrm{Y}$ cells were placed in the incubator outside and inside the coil, respectively. Cells were exposed to $50-\mathrm{Hz}$ EMF at 0.5 and $1 \mathrm{mT}$ for 3 hours in a day.

\section{Preparation}

After 3 hours of exposure to $50 \mathrm{~Hz}$ ELF-EMF with different intensities, SH-SY5Y cells were harvested by centrifugation at $3000 \mathrm{rpm}$ for 10 minutes, washed 3 times with washing buffer $(10 \mathrm{mM}$ Tris $\mathrm{pH} 7.0$ and $250 \mathrm{mM}$ $\mathrm{D}$-sorbitol) and then resuspended in standard lysis buffer (8M urea, 4\% CHAPS, $40 \mathrm{mM}$ DTT, 2\% pharmalyte (pH 3-10 NL), 1 mM PMSF and 1 mM EDTA). Samples were sonicated with a sonicator probe for 5 minutes and centrifuged at $40000 \mathrm{~g}$ for 30 minutes at $4^{\circ} \mathrm{C}$. Protein concentration in collected supernatants was determined using Bradford's method. After quantification of proteins, the supernatants were kept at $-20^{\circ} \mathrm{C}$ until electrophoresis.

\section{Two-Dimensional Gel Electrophoresis}

The extracted protein was separately mixed with rehydration buffer and applied to a $17 \mathrm{~cm}$ immobilized $\mathrm{pH}$ gradient (IPG) strip, $\mathrm{pH} 3-10$, and was passively rehydrated with the above sample solution overnight at room temperature. Isoelectric focusing (IEF) was performed in 5 steps including $150 \mathrm{~V}, 1$ hour, $300 \mathrm{~V}, 1$ hour, $1000 \mathrm{~V}$, 1 hour, $5000 \mathrm{~V}, 2$ hours (in a gradient pattern) and 5000 V, 2 hours. Following IEF, IPG strips were incubated in equilibration buffer containing $6 \mathrm{M}$ urea, $30 \%$ glycerol, $2 \%$ SDS, $2 \%$ DTT and then alkylated for 20 minutes in the same buffer with $2.5 \%$ iodoacetamide instead of DTT. In the second dimension, the treated strips were transferred onto $12 \%$ SDS-polyacrylamide slab gel and sealed with $1 \%$ agarose. The gels ran in $2.5 \mathrm{~W}$ for 30 minutes and then 15 $\mathrm{W}$ until the bromophenol blue reached the end of the gel. Analytical gels were stained with Coomassie brilliant blue staining. Gels were scanned using Bio Rad Image Scanner and Spot detection, matching; and quantitative gel analysis was carried out with Nonlinear Progenesis software.

\section{Results}

Since cell morphology and proliferation can be affected by ELF-EMF exposure, the SH-SY5Y cells were exposed to $50 \mathrm{~Hz}$ ELF-EMF ( 0.5 and $1 \mathrm{mT}$ ) for 3 hours. Cell morphology alteration was analyzed using microscopic assessments (Figure 1). The findings corresponded to an inhibition of cellular proliferation rate (data not shown). Cell morphology changes and cell proliferation alteration may be associated with changes in gene expression regulation, therefore proteomes of neuroblastoma cells exposed to 50 $\mathrm{Hz}$ ELF-EMF with 2 different intensities ( 0.5 and $1 \mathrm{mT}$ ) for 3 hours were provided. In the 2-DE technique, proteins were separated according to the $\mathrm{pI}$ and molecular weight in the first and second dimensions, respectively. The gels of the exposed ( 0.5 and $1 \mathrm{mT})$ and control cells are shown in Figure 2. The protein patterns on the gels were analyzed using Progenesis SameSpots software. With this software, the control gel was compared to ELF-EMF exposed gels. The findings indicate that gene expression is affected by exposure and it is a dose dependent process. Sixty-four and 40 genes were up regulated and down regulated respectively, after the cells were exposed to 0.5 $\mathrm{mT}$ of $50 \mathrm{~Hz}$ radiation $(P<0.05)$. The expression of 151 genes significantly differed when the cells were exposed to $50 \mathrm{~Hz}, 1 \mathrm{mT}$ for 4 hours $(P \leq 0.05)$, including 86 upregulated and 65 downregulated genes. Up and down regulated proteins can be grouped based on their expression
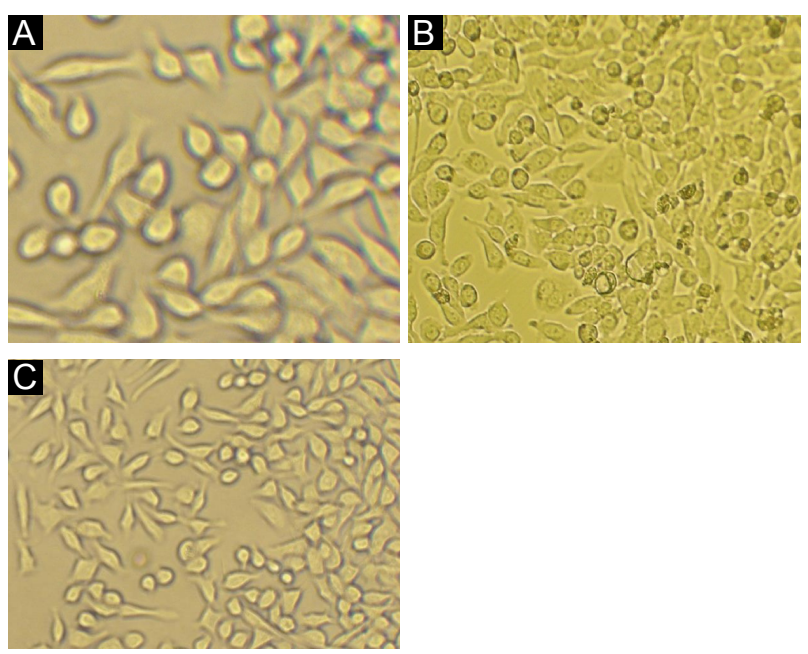

Figure 1. Morphological Responses of (A) Exposed SH-SY5Y Cells to $50 \mathrm{~Hz}, 0.5 \mathrm{mT}$, (B) $50 \mathrm{~Hz}, 1 \mathrm{mT}$ and (C) Control Cells. 

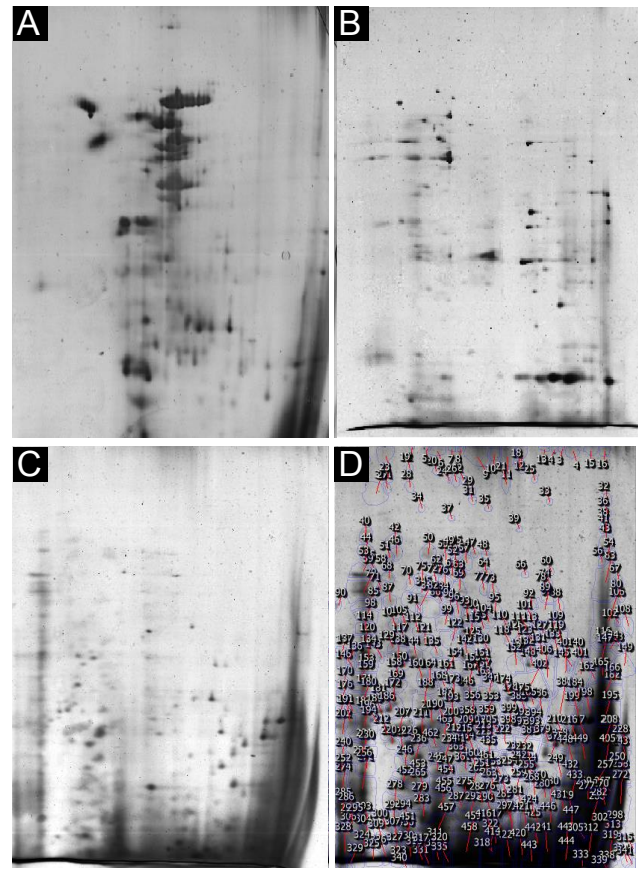

Figure 2. Electrophoresis Feature of Exposed SH-SY5Y Cells to (A) $50 \mathrm{~Hz}, 0.5 \mathrm{mT}$, (B) $50 \mathrm{~Hz}, 1 \mathrm{mT}$ and (C) Control Cells. The gel of normal cells is selected as reference gel (D).

pattern via hierarchical clustering. The results can be presented in a dendrogram tree in which similar expression patterns cluster together. Statistical analysis by Progenesis SameSpot was performed via hierarchical cluster analysis and principal components analysis (PCA) (Figures 3-6).

\section{Discussion}

Dendrograms of clustered proteins are represented in Figure 3. As depicted in this figure, the range changes of expression in down regulated proteins is wider than in up regulated proteins. After exposure $(0.5$ and $1 \mathrm{mT})$, the number of up regulated proteins was higher than the down regulated proteins (about 1.3 and 1.6 fold). As showed by the results we reported, exposure leads to up regulation relative to down regulation. However, the number of proteins which regulation are changed might be not as current work as the differences may be related to the fact that responses to exposure can be irregular.

In order to determine if there are any outliers in the data and verify the quality of the replicates, PCA was used. The results showed that there are no outliers in the protein set of both groups.

Since cell morphology and function are closely related, in this study, the potential effect of $50 \mathrm{~Hz}$ electromagnetic wave on SHSY5Y cell morphology and relevant proteomes' profile was investigated. As it is depicted in Figure 1, exposure to $50 \mathrm{~Hz}$ ELF-EMF can affect cell morphology and increasing intensity causes a complete decrease in cell proliferation. It can be considered that 50 $\mathrm{Hz}$ exposure affects cell function and survival in a dose dependent manner. Moreover, we determined possible changes in the expression levels of proteins at 2 intensi-

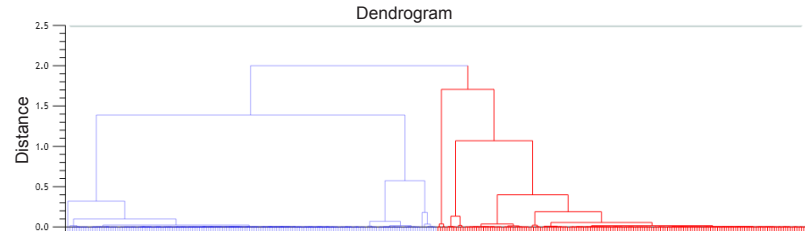

Figure 3. Clustered Proteins Exposed SH-SY5Y Cells to $50 \mathrm{~Hz}, 0.5$ $\mathrm{mT}$. The up regulated proteins are presented in red color and the down regulated proteins are shown in blue color.

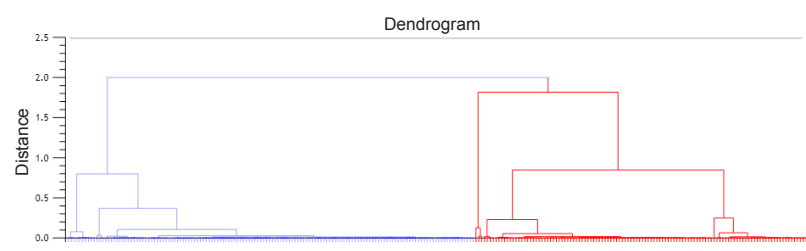

Figure 4. Clustered Proteins Exposed SH-SY5Y Cells to $50 \mathrm{~Hz}, 1$ $\mathrm{mT}$. The upregulated proteins are presented in red color and the down regulated proteins are shown in blue color.

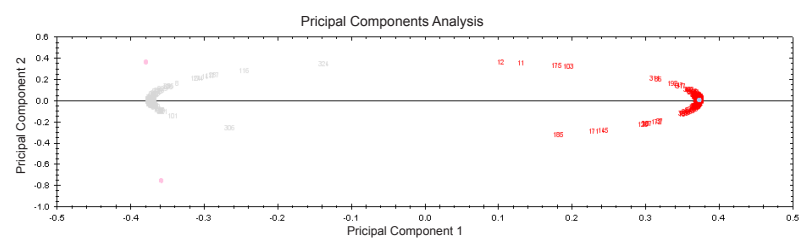

Figure 5. Principal Components Analysis in Exposed Cells to 50 $\mathrm{Hz}, 0.5 \mathrm{mT}$. The up regulated proteins are shown in red color and the down regulated proteins are represented in gray color.

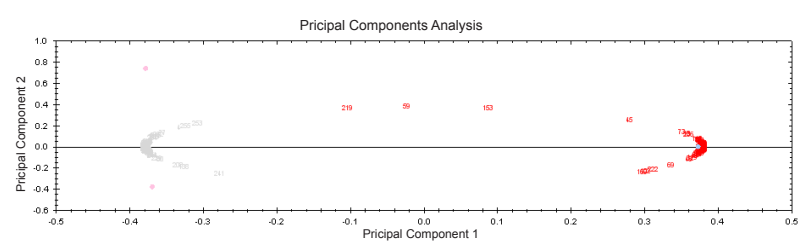

Figure 6. Principal Components Analysis in Exposed Cells to 50 $\mathrm{Hz}, 1 \mathrm{mT}$. The upregulated proteins are shown in red color and the down regulated proteins are represented in gray color.

ties $(0.5$ and $1 \mathrm{mT})$ of $50 \mathrm{~Hz}$ ELF-EMF. As depicted in Figure 2, our data indicated that protein expression changes (proteome profiles) are highly dependent to the intensity of exposure. Gel analysis was performed with Progenesis SameSpot software. Proteomics is a powerful technique that can help determine the molecular mechanism of exposure. ${ }^{19-21}$ Clustering, as an analytical tool in proteomics, can provide an informative view of molecular categories. ${ }^{19}$ In spite of different studies, there are a few researches that have investigated the biological effects and underlying mechanism of exposure to ELF-EMF via proteomics. $^{22-24}$ For more than 30 years several epidemiological and experimental studies have been performed in order to detect the potential effect of exposure to ELF EMF. ${ }^{1,2,5}$ Controversial data might be due to different exposure frequencies, intensities, timing and also certain types of cell line. ${ }^{17}$ As it is shown in Figures 3 and 4, clustering of the changed expression proteins indicates that 
the clustering pattern is highly dependent to the dose intensity. It seems that variation in the number of clusters is reduced (specially for down regulated proteins), which corresponds to the increment of intensity. This finding refers to the nearly equal response of the genes to high intensity doses. Neuronal cells are responsive and sensitive to environmental exposure, therefore some experimental studies were carried out on gene expression of these cell types. There are a few studies on neroublastoma cells using proteomics. ${ }^{23,25}$ However, the findings cannot be compatible with our results; this is because of the various cell responses which are related to several parameters such as intensity and pattern of exposure. As mentioned in the results, 2 important points are to be considered; first, the number of affected genes in higher intensity are $45 \%$ higher than in low intensity; and second, the ratio of up regulated genes to down regulated genes are 1.6 and 1.3 in 0.5 and $1 \mathrm{mT}$, respectively. It can be concluded that radiation effects as an undesired stress and higher intensity level of ELF-EMF exposure correspond to higher stress strength. In conclusion, the results of this study indicate that cell morphology and gene expression can be affected by ELF-EMF exposure and depend on exposure intensity. The other finding corresponds to the more stimulatory role relative to the inhibitory effect of ELF-EMF exposure on gene expression.

\section{Ethical Consideration}

This project was confirmed by Ethic Committee of Shahid Behesti University of Medical Sciences (Code No. IR.SBMU.RETECH.1395.671).

\section{Conflict of interest}

The authors report no conflict of interest.

\section{Acknowledgment}

This work was made possible by a common research grant provided by Shahid Beheshti University of Medical Sciences and Semnan University of Medical Sciences.

\section{References}

1. Grellier J, Ravazzani P, Cardis E. Potential health impacts of residential exposures to extremely low frequency magnetic fields in Europe. Environ Int. 2014;62:55-63. doi:10.1016/j. envint.2013.09.017.

2. Karasek M, Woldanska-Okonska M. Electromagnetic fields and human endocrine system. ScientificWorldJournal. 2004;4 Suppl 2:23-28. doi:10.1100/tsw.2004.175

3. Ivancsits S, Diem E, Pilger A, Rudiger HW, Jahn O. Induction of DNA strand breaks by intermittent exposure to extremely-low-frequency electromagnetic fields in human diploid fibroblasts. Mutat Res. 2002;519(1-2):1-13.

4. Cuccurazzu B, Leone L, Podda MV, et al. Exposure to extremely low-frequency $(50 \mathrm{~Hz})$ electromagnetic fields enhances adult hippocampal neurogenesis in C57BL/6 mice. Exp Neurol. 2010;226(1):173-182. doi:10.1016/j. expneurol.2010.08.022.

5. Kheifets L, Ahlbom A, Crespi CM, et al. Pooled analysis of recent studies on magnetic fields and childhood leukaemia.
Br J Cancer. 2010;103(7):1128-1135.

6. Schuz J. Exposure to extremely low-frequency magnetic fields and the risk of childhood cancer: update of the epidemiological evidence. Prog Biophys Mol Biol. 2011;107(3):339-342.

7. Zaryabova V, Shalamanova T, Israel M. Pilot study of extremely low frequency magnetic fields emitted by transformers in dwellings. Social aspects. Electromagn Biol Med. 2013;32(2):209-217.

8. Wolf FI, Torsello A, Tedesco B, et al. 50-Hz extremely low frequency electromagnetic fields enhance cell proliferation and DNA damage: possible involvement of a redox mechanism. Biochim Biophys Acta. 2005;22:1-2.

9. Ruiz Gomez MJ, De la Pena L, Pastor JM, Martinez Morillo M, Gil L. 25 Hz electromagnetic field exposure has no effect on cell cycle distribution and apoptosis in U-937 and HCA2/1cch cells. Bioelectrochemistry. 2001;53(1):137-140.

10. Falone S, Grossi MR, Cinque B, et al. Fifty hertz extremely low-frequency electromagnetic field causes changes in redox and differentiative status in neuroblastoma cells. Int J Biochem Cell Biol. 2007;39(11):2093-2106. doi:10.1016/j. biocel.2007.06.001.

11. Piacentini R, Ripoli C, Mezzogori D, Azzena GB, Grassi C. Extremely low-frequency electromagnetic fields promote in vitro neurogenesis via upregulation of $\mathrm{Ca}(\mathrm{v}) 1$-channel activity. J Cell Physiol. 2008;215(1):129-139.

12. Singh N, Lai H. $60 \mathrm{~Hz}$ magnetic field exposure induces DNA crosslinks in rat brain cells. Mutat Res. 1998;400(12):313-320.

13. Winker R, Ivancsits S, Pilger A, Adlkofer F, Rudiger HW. Chromosomal damage in human diploid fibroblasts by intermittent exposure to extremely low-frequency electromagnetic fields. Mutat Res. 2005;585(1-2):43-49.

14. Seyyedi SS, Dadras MS, Tavirani MR, Mozdarani H, Toossi P, Zali AR. Proteomic analysis in human fibroblasts by continuous exposure to extremely low-frequency electromagnetic fields. Pak J Biol Sci. 2007;10(22):41084112.

15. Reale M, Kamal MA, Patruno A, et al. Neuronal cellular responses to extremely low frequency electromagnetic field exposure: implications regarding oxidative stress and neurodegeneration. PLoS One. 2014;9(8):e104973. doi: 10.1371/journal.pone.0104973.

16. Griffin GD, Khalaf W, Hayden KE, et al. Power frequency magnetic field exposure and gap junctional communication in Clone 9 cells. Bioelectrochemistry. 2000;51(2):117-123.

17. Vianale G, Reale M, Amerio P, Stefanachi M, Di Luzio S, Muraro R. Extremely low frequency electromagnetic field enhances human keratinocyte cell growth and decreases proinflammatory chemokine production. $\mathrm{Br}$ J Dermatol. 2008;158(6):1189-1196. doi:10.1111/j.13652133.2008.08540.x.

18. Antonini RA, Benfante R, Gotti C, et al. Extremely lowfrequency electromagnetic field (ELF-EMF) does not affect the expression of alpha3, alpha5 and alpha7 nicotinic receptor subunit genes in SH-SY5Y neuroblastoma cell line. Toxicol Lett. 2006;164(3):268-277. doi:10.1016/j. toxlet.2006.01.006.

19. Marengo E, Leardi R, Robotti E, Righetti PG, Antonucci F, Cecconi D. Application of three-way principal component analysis to the evaluation of two-dimensional maps in proteomics. J Proteome Res. 2003;2(4):351-360.

20. Zali H, Rezaei Tavirani M, Azizi Jalilian F, Khodarahmi R. 
Proteins expression clustering of Alzheimer disease in rat hippocampus proteome. J Paramed Sci. 2013;4(3):111-118.

21. Azodi MZ, Rezaie-Tavirani M, Heydari-Kashal S, Kalantari S, Dailian S, Zali H. Proteomics analysis of MKN45 cell line before and after treatment with Lavender aqueous extract. Gastroenterol Hepatol Bed Bench. 2012;5(1):35-42.

22. Rostami A, Shahani M, Zarrindast MR, et al. Effects of $3 \mathrm{~Hz}$ and $60 \mathrm{~Hz}$ extremely low frequency electromagnetic fields on anxiety-like behaviors, memory retention of passive avoidance and electrophysiological properties of male rats. J Lasers Med Sci. 2016;7(2):120-1255. doi: 10.15171/ jlms.2016.20.

23. Hasanzadeh H, Rezaie-Tavirani M, Seyyedi S, et al. Effect of ELF-EMF exposure on human neuroblastoma cell line: a proteomics analysis. Iran J Cancer Prev. 2014;1:22-27.

24. Sinclair J, Weeks M, Butt A, et al. Proteomic response of Schizosaccharomyces pombe to static and oscillating extremely low-frequency electromagnetic fields. Proteomics. 2006;6(17):4755-4764. doi:10.1002/pmic.200500861

25. Benfante R, Antonini RA, Kuster N, et al. The expression of PHOX2A, PHOX2B and of their target gene dopaminebeta-hydroxylase (DbetaH) is not modified by exposure to extremely-low-frequencyelectromagnetic field (ELFEMF) in a human neuronal model. Toxicol In Vitro. 2008;22(6):1489-1495. doi:10.1016/j.tiv.2008.05.003. 